\title{
Body Fat Distribution, Serum Leptin, And Insulin Resistance In Obese Subjects With Obstructive Sleep Apnoea.
}

\author{
Hassan ZA*,Attia MF**, Ahmed AH**;Hassan HA***, \\ Amer $\mathbf{H}^{* * * * *}$; \\ Endocrinology*and General Medicine*** Departments, Alazhar University (girls), \\ ENT Department** Alazhar university (boys), Clinical pathology Department**** \\ Ain Shams University.
}

\begin{abstract}
Obstructive sleep apnoea $(\mathrm{OS} A)$ is strongly associated with obesity and is characterized by endocrine and metabolic changes.

The aim of the present study is to clarify whether there is interrelationship between body fat, serum leptin, glucose-insulin metabolism and OSA.

Subjects and measurements: we studied 23 obese subjects with OSA (13 males, \& 10 females; age mean $36 \pm 4.4$ years; BMI: $31.7 \pm 3.6 \mathrm{~kg} / \mathrm{m} 2$; WHR: $1.2 \pm .25$ in males and $0.81+.5$ in females ;Apnoea Index "AI" $(9.2 \pm 6.1)$ event/hour of sleep by means of overnight polysomnography; fasting glucose $(109.8 \pm 21.4 \mathrm{mg} / \mathrm{dL})$; fasting insulin $(18.6 \pm 7.1 \mathrm{uU} / \mathrm{L})$; IR(6.7 \pm 2.8$)$; fasting leptin $(577.69 \pm 201.6 \mathrm{ng} / \mathrm{ml})$. Results were compared with those of 10 healthy normal weight subjects $(6$ males, 4 females ;age mean $36.8 \pm 4.4$ years; BMI: $25 \pm 0.24$ $\mathrm{kg} / \mathrm{m} 2$; WHR: $0.86 \pm 0.01$; AI: $2.1 \pm 1.1$ event/hour; fasting glucose $(71.7 \pm 2.8 \mathrm{mg} / \mathrm{dL})$; fasting insulin( $15.3 \pm .48 \mathrm{uU} / \mathrm{L}) ; \operatorname{IR}(4.6 \pm .17)$; fasting leptin $(42.4 \pm 11.5 \mathrm{ng} / \mathrm{ml})$.
\end{abstract}

Results: Anthropometric measurements of OSA subjects were highly significantly greater than controls; body weight $(\mathrm{P}<0.003)$; BMI $(\mathrm{P}<0.00)$; waist $(\mathrm{P}<0.000)$; and WHR $(\mathrm{P}<0.000)$. Fasting glucose levels; fasting plasma insulin; IR and leptin levels were significantly higher in OSA subjects than controls $(\mathrm{P}<0.000,0.03,0.002 ; \& 0.000)$ respectively. Overnight polysomnography revealed significant difference between OSA subjects and controls as regards AI $(\mathrm{P}<0.001)$.

The major dependent outcome variable was the apnoea index (AI), "the average number of apnoeas per hour of sleep determined by overnight polysomnography". OSA was defined as AI $\geq 5$. Highly significant correlation between AI and WHR $(\mathrm{P}<0.00)$; Fasting insulin $(\mathrm{P}<0.04)$; IR $(\mathrm{P}<001)$ and Leptin $(\mathrm{P}<0.000)$ were detected. Also leptin concentrations correlated with fasting insulin $(\mathrm{P}<0.02)$; IR $(\mathrm{P}<0.00)$ and WHR $(\mathrm{P}<0.000)$ besides the AI.

IN CONCLUSION: There is strong bidirectional, feed-forward pernicious correlation detected between OSA in one side and each of visceral obesity, leptin, and IR; also between leptin, obesity, and IR. This association may contribute to the pathological manifestations and somatic sequale of this condition.

Leptin could have major role linking OSA with various metabolic abnormalities detected in obese subjects.

High circulating leptin found in this study, suggests that both obesity and OSA may be caused by a leptin resistant state.

Among obese subjects, it is visceral fat (WHR), rather than generalized obesity (BMI) that predisposes to OSA.

\section{Introduction}

Obstructive sleep apnoea syndrome (OSAS) is a common disorder characterized by disruptive snoring, frequent episodes of apnoea and hypopnea during sleep.
Approximately, $1-10 \%$ of men and $2 \%$ of women have OSA as defined by apnoea hypopnoea index $\geq 5$ and daytime hypersomnolence (Young et al, 1993). The 
prevalence of OSA is increased fourfold in patients with obesity. Obesity in adults is closely linked to a number of diseases that causes significant morbidity and mortality, including type 2 diabetes, ischaemic heart disease, hypertension and dyslipidaemia (Meig, 2000). However, as previous studies have only considered these variables individually, it has not been possible to determine the over all association of OSA with this syndrome (Steven et al, 2004).

Numerous hormones modulate fat storage through their effects on energy balance. Adipose tissue secretes leptin which participates in the regulation of multiple metabolic pathways (Spiegelmanand Flier, 1996), as well as in the obesity hypoventilation syndrome (Phipps et al, 2002). ९Aim Of The Work

The aim of the present study was to analyze the relationship between OSA and obesity, leptin, and glucose-insulin metabolism. Also among obese patients, is it generalized or visceral obesity that predisposes to sleep apnoea.

\section{Subjects And Methods}

Subjects: This study was conducted on 23 obese subjects (13 males and 10 females), age range 28-42 years. They were referred to the sleep laboratory for snoring and suspected OSA. Subjects were eligible if they were not known to suffer from any medical condition, receiving medications, and were other wise healthy. Ten normal weight subjects (6 males, and 4 females), served as controls.

A comprehensive physical examination was performed. During a single overnight hospitalization, a sleep study was performed, anthropometric measurements and fasting blood samples were taken.

\section{Methods: -}

\section{*Sleep Studies:}

Subjects underwent an overnight home-based level III sleep study using the Sleep Apnea Monitor (SAM) (Intercare Technologies, Inc., Milwaukee, WI).
Detailed instructions on the use of this device, proper fit, and calibration were provided during an in-office session coordinated by a trained medical assistant. During the night of the study, a diary was maintained to describe nocturnal events that might interrupt data acquisition, such as going to the bathroom, awakening for a prolonged period; or an equipment failure. The SAM unit measured the following parameters: nasal airflow, respiratory effort via both chest wall and abdominal strain detectors 5 oxygen saturation, snoring, and heart rate and body position.

Standard nocturnal polysomnography was performed with recording of sleep stages (EEG, chin muscle electromyography, electrooculography); measurements of oro-nasal airflow, snoring, respiratory movements, and oxygen saturation with a finger pulse oximeter. Apnoea was marked when air flow amplitude was $<20 \%$ of the base line, to hypopnoea when amplitude was $20 \%$-to $60 \%$ of the base line. Respiratory events were designated obstructive if respiratory efforts persisted on diaphragm EMG and/or chest and abdominal movements, or central if there were no respiratory effort. OSA was diagnosed by a combination of clinical history and polysomnography with an apnoea index $\geq 5$.

Height (to the nearest $0.5 \mathrm{~cm}$ ) and weight (to the nearest $0.5 \mathrm{~kg}$ ) were recorded. Body mass index (BMI) was calculated as weight/height $\mathrm{m} 2$. Each subject waist was measured mid way between the lowest rib and the iliac crest. Hip circumference was measured at the widest of the gluteal region. Waist / Hip ratio, (WHR), was calculated.

\section{*Hormonal Studies:}

On the night of the sleep study, patients fasted from 12PM till blood collection at $8 \mathrm{AM}$. Serum level of glucose, insulin and leptin were measured. Serum glucose was measured by the hexokinase method on Synchron CX7 autoanalyzer (Beckman Inst. Inc. Serum insulin was measured by using a double antibody 125 I radioimmunoassay kit supplied by ICN Diomedicals Inc. Serum leptin concent- 
rations were determined by a competitive enzyme immunoassay method using the Medizyme Kit supplied by Medipan Diagnostica.

\section{Statistical Methods}

Statistical analysis of the results was done using SPSS software package version 10 . Data was first tested for normal distribution and the student " $t$ " test was applied to compare the means of normally distributed data. Correlations were evaluated by Spearman's Rank correlation.

\section{Results}

Table (1): Comparison Between " OSA" Patients And Controls As Regards Anthropometric, Hormonal, And Sleep Apnoea Parametres.

\begin{tabular}{|c|c|c|c|}
\hline $\begin{array}{r}\text { Studied } \\
\text { Group }\end{array}$ & OSA patients (n+23) & CONTROLS (n+10) & P-value \\
\hline Variable & & & \\
\hline AGE (yrs) & $36.0 \pm 10.17$ & $36.8 \pm 4.4$ & $>0.05$ \\
\hline HEIGHT (cm) & $172.7 \pm 6.87$ & $175.5 \pm 10.9$ & $>0.05$ \\
\hline WEIGHT kg & $92.08 \pm 11.8$ & $79.9 \pm 6.47$ & $0.003^{*}$ \\
\hline BMI (KG/m2) & $31.7 \pm 3.6$ & $25 \pm 0.24$ & $0.000^{*}$ \\
\hline WAIST (cm) & $112.0 \pm 11.1$ & $92.3 \pm 4.3$ & $0.000^{*}$ \\
\hline HIP (cm) & $106.52 \pm 8.1$ & $108.3 \pm 6.11$ & $>0.05$ \\
\hline W/H R & $1.2 \pm 0.24$ & $0.87 \pm 0.01$ & $0.000^{*}$ \\
\hline FBS mg/dl & $109 \pm 21.4$ & $71.7 \pm 2.8$ & $0.000^{*}$ \\
\hline INSULIN uU/L & $18.6 \pm 7.1$ & $15.3 \pm 4$ & $0.03^{*}$ \\
\hline IR & $6.7 \pm 2.8$ & $4.6+.17$ & $0.002^{*}$ \\
\hline LEPTIN ng/ml & $577.69 \pm 201$ & $42.4 \pm 11.5$ & $0.000^{*}$ \\
\hline AI & 9.2 & 2.0 & $0.001^{*}$ \\
\hline
\end{tabular}

Table ( 2 ): Correlation Between Apnea Index And Waist Hip Ratio, Insulin Resistance, And Leptin.

\begin{tabular}{|c|c|c|c|}
\hline $\mathbf{1}^{\text {st }}$ Variable & $\mathbf{2}^{\text {nd }}$ Variable & $\mathbf{r}$ & $\mathbf{p}$ \\
\hline Apnoea Index & W/H R & 843 & $0.000^{*}$ \\
\hline & I R & .632 & $0.001^{*}$ \\
\hline & Leptin & 889 & $0.000^{*}$
\end{tabular}

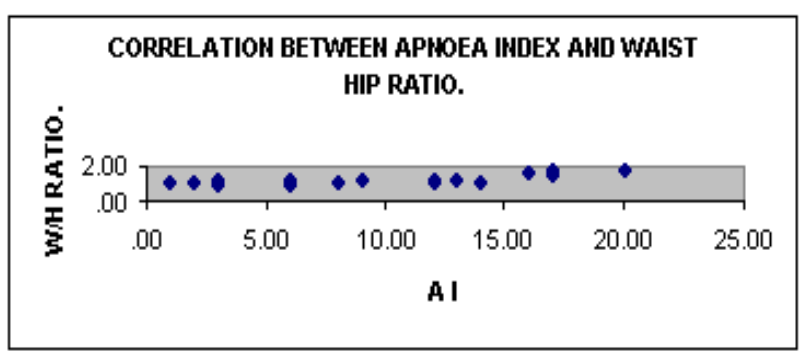



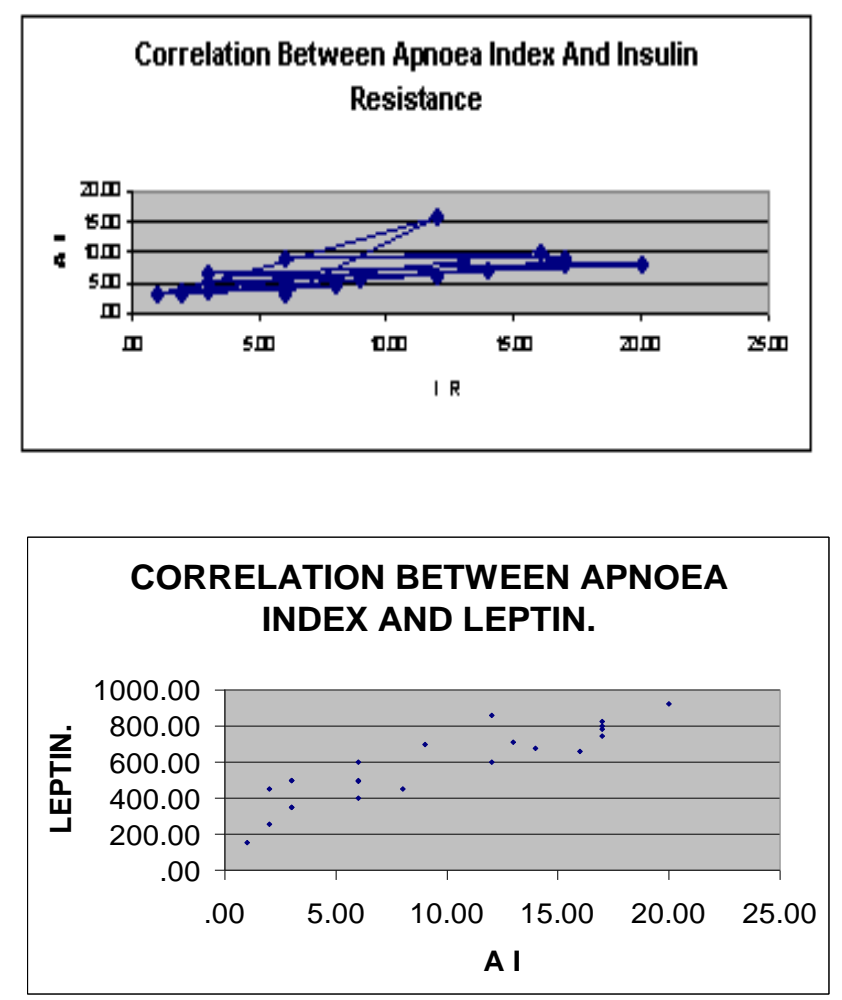

Table ( 3 ): Correlation Between Leptin And Waist Hip Ratio, Insulin Resistance, Fasting Glucose And Insulin.

\begin{tabular}{|c|c|c|c|}
\hline $\mathbf{1}^{\text {st }}$ Variable & $\mathbf{2}^{\text {nd }}$ Variable & $\mathbf{r}$ & $\mathbf{p}$ \\
\hline Leptin & W/H R & 693 & $0.000^{*}$ \\
\hline & I R & 703 & $0.000^{*}$ \\
\hline & Fasting glucose & .178 & .417 \\
\hline & Fasting insulin & -187 & .394 \\
\hline
\end{tabular}
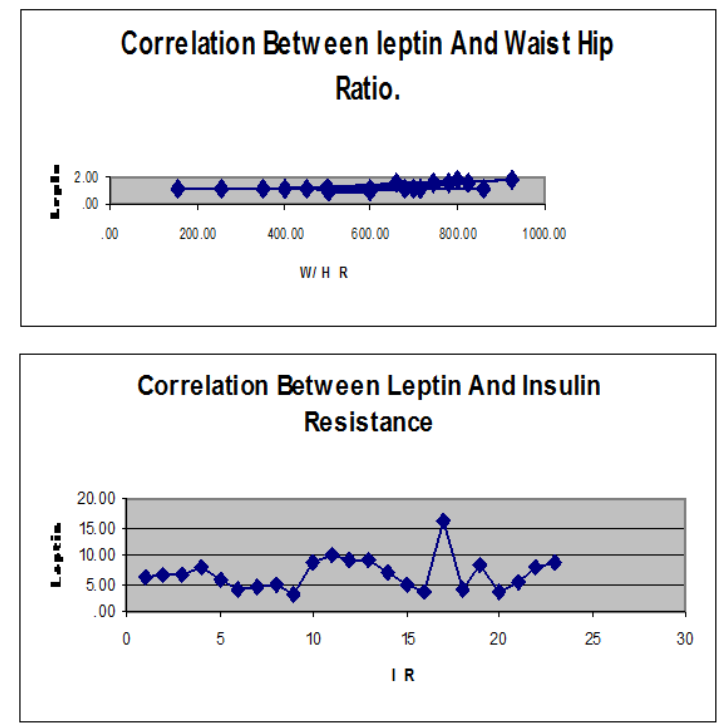


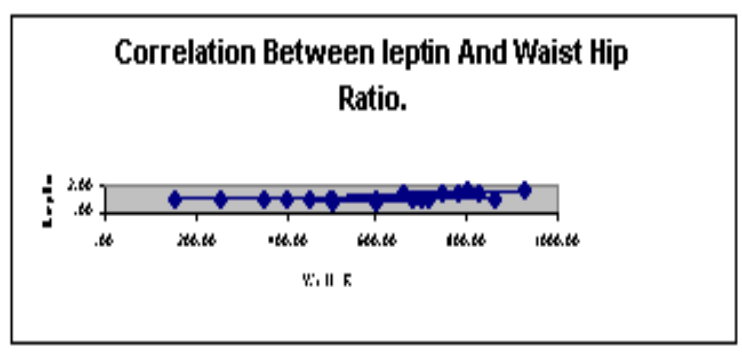

Table ( 4 ): Correlation Between Insulin Resistance. And Waist Hip Ratio,

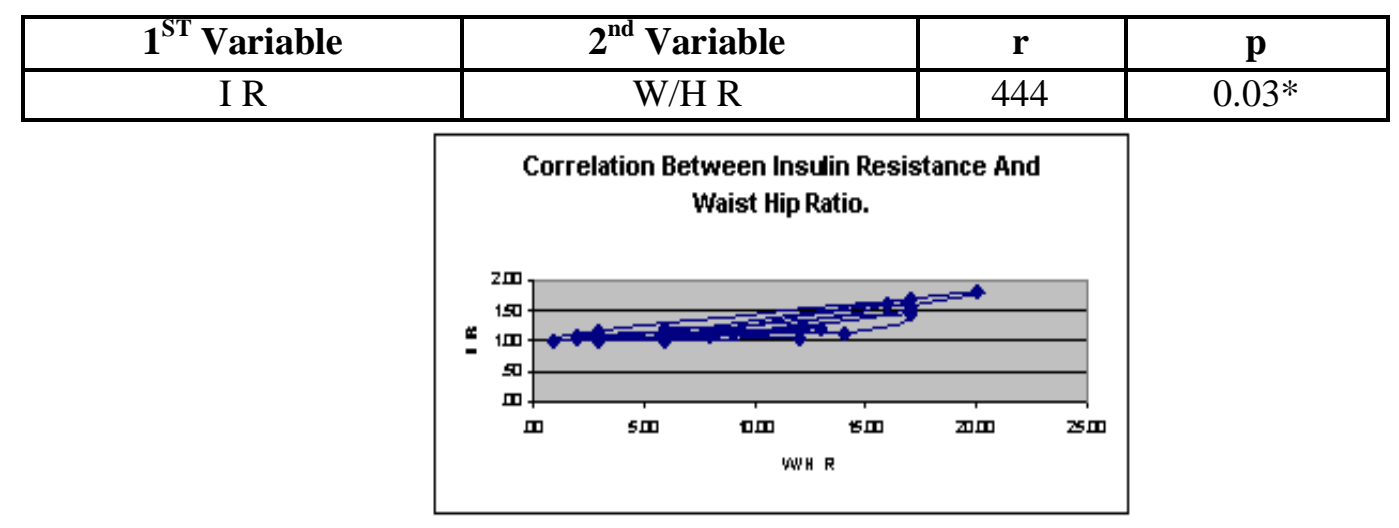

\section{Discussion}

OSA is a common disorder. Obesity clearly plays an important role in sleep-disordered breathing, and an increase of 1-SD in any measure of body habitus is associated with a 3-fold increase in the risk of an apnoeahypopnoea score of 5 or higher(Young et al, 1993).

In the present study, the major dependent outcome variable was the apnoea index AI. OSA was defined as an apnoea index $\geq 5$ event/hour of sleep by means of overnight polysomnography. Our results showed highly significant correlation between the degree of AI and WHR in OSA subjects, while no other significant correlations were found with the other anthropometric measures of obesity as body weight and BMI. Solomon and Manson, (1997) stated that central fat accumulation is frequently estimated by WHR. While (Lane et al, 2004) found positive correlation between AI and all anthropometric parameters, yet ,our findings are consistent with those reported by Grunstan et al, (1993); Alexandros et al,(2000); and Steven
(2004); who found that visceral (central) fat has been associated more with OSA than other forms of obesity.

So our results suggest that among obese individuals, it is visceral fat (WHR), rather than generalized obesity (BMI) that predisposes to the development of OSA.

Adipose tissue secretes leptin which is best known as a regulator of energy homeostasis, also it interacts with sleep and breathing. Leptin is a powerful respiratory stimulant (Fitzpatrick, 2002 and Chin, 2000). Serum leptin levels correlates positively with total body mass (Phipps et al 2002).

In the current study, significant difference was found between serum leptin levels, being higher, in OSA subjects compared to controls. Also highly significant positive correlation was found between the AI and serum leptin level. Our findings are in accordance with results obtained by Phipps et al, (2002); Schafer et al, (2002); Bradly et al, (2000); and Chin et al, (1999).

One explanation might be that AI can be considered an indicator of the degree of 
physiologic stress caused by sleep disordered breathing .Stress may lead to increased leptin levels through an increase in leptin secretion (Schafer et al, 2002).

High prevalence of OSA in obese humans and the established role of leptin as a respiratory stimulant and appetite suppressant, raised the possibility that sleep apnoea could be a leptin deficient state. High circulating leptin found in this study and others, suggest that both obesity and OSA may be caused by a leptin resistant state.

In the current study, significant correlation between leptin and regional fat distribution (WHR) was found, besides, their significant higher level in OSA subjects than controls. These findings are in agreement with (Schafer et al, 2002; Alexandros et al, 2000; and Chin et al, 1999 ).

Our findings suggest that the increase in leptin levels in sleep apnoea is possibly related to their higher amount of visceral fat.

The correlation between AI and leptin levels found in this study, may thus represent the link between body fat distribution and the development of OSA.

Fasting insulin levels are used as a measure of insulin resistance, consistent with other population studies .To optimize correlations, formulas that combine insulin with other metabolic indices (e.g. triglycerides, or glucose)in the homeostasis model assessment are used. These formulas did not improve correlations in our study and the frequent sampling required for the glucose clamp technique was not possible. So, in this study insulin sensitivity was evaluated by the ratio of fasting glucose (G0) to fasting insulin (I0) (Mislier, 2003).

In the current study, fasting glucose and insulin levels were significantly higher in OSA subjects, who were also more insulin resistant than controls. Our results are in agreement with (Alexandros et al, 2000; and Vgontaset et al, 2003 ) while, (Strohl et al, 1994) reported opposite results. Inflammatory cytokines TNF- $\alpha$ and IL-6, are elevated in sleep apnoea and obesity. These cytokines causes marked insulin resistance and stimulates insulin secretion (Alexandros et al,2000).
In this study, we have demonstrated that AI was significantly correlated with insulin levels and was highly significant with insulin resistance .These results are in agreement with those found by (Stoohs $e t$ al, 1996); and (Grunstein et al, 1995).A popular hypothesis is that hypoxia leads to an increased sympathetic neural discharge and, thus, to insulin resistance (Bradly et al, 2000). Strohl et al, (1993); suggested that the events of OSA such as apnoea/ hypopnoea index or oxygen desaturation, may lead to insulin resistance via increased catecholamines or cortisol.

Also we can suggest that the relation between OSA and serum insulin or insulin resistance reflect the known effect of obesity. Brooks et al, (1994) in his study, showed that patients with OSA and type 2 diabetes, treated with continuous positive airway pressurs "CPAP", had improved insulin sensitivity. These data suggest that there is an effect of OSA on insulin resistance apart from the effect of coexistent central obesity.

Furthermore, Vgontzas et al, (2003) found that women with PCOS were much more likely than controls to have sleep disordered breathing, supporting the pathogenetic role of insulin resistance in OSA. So accumulating evidence provides support of the bidirectional, feed-forward, pernicious association between OSA and insulin resistance.

The relationship between serum leptin with insulin resistance and fasting glucoseinsulin was studied. Our results revealed that fasting leptin was directly correlated with insulin resistance, and inversely correlated with insulin, while no correlation was detected with fasting glucose level. These results are in accordance with (Schafer et al, 2002; and de Courten et al, 1997).

Studies by Walder et al, (1997); showed that leptin decreases total insulin binding in adipocytes and possible inhibition of insulin secretion by the pancrease (Emilsson et al,1997). So leptin may play a role in modulating insulin action and sensitivity. On the other hand, chronic hyperinsulinemia was found to increase 
leptin levels (Considin and Van Gaal, 2000).

Given the close correlation of leptin with indices of adipose tissue, and between leptin and parameters of glucose metabolism, especially, insulin resistance ; we can suggest an association between leptin, obesity and the metabolic abnormalities in OSA subjects and that hyperleptinemia rather than insulin resistance alone might be another key driving force for these abnormalities.

\section{In Conclusion:}

visceral obesity, hyperleptinemia, and insulin resistance may be the principle factor leading to worsening of the metabolic manifestations and sleep apnoea. Progressive deterioration of sleep apnoea may then accelerate the worsening of obesity and metabolic abnormalities.

High circulating leptin found in this study, suggests that both obesity and OSA may be caused by a leptin resistant state.

Among obese subjects, it is visceral fat (WHR), rather than generalized obesity (BMI) that predisposes to OSA.

\section{References}

1. Alexandros N, Dimitris A, Edward O, Kenneth $\mathbf{H}$, et al. Sleep apnoea and daytime sleepiness and fatigue: relation to visceral obesity, insulin resistance, and hypercytokinemia. J clin endocrinol \& metabol. 2000; 85(3) 1151-1158.

2. Bradley G, Masahiko K, Krzysztof N, Ian $\mathbf{C}$, and Virend $\mathbf{S}$. Increase in leptin levels, sympathetic drive, and weight gain in obstructive sleep apnoea. AJP-Heart and Circulatory Physiology 2000; 279(1): H234-H237.

3. Brooks B, Cistulli P, Borkman M. Effect of nasal continuous positive airway pressure treatment on insulin sensitivity in patients with type 2 diabetes and obstructive sleep apnoea.J clin endo metab. 1994; 79: 1681-1685.

4 Chin K, Shimizu K, Nakamura T, Narai $\mathbf{N}$, et al. Changes in intra-abdominal visceral fat and serum leptin levels in patients with obstructive sleep apnoea syndrome following nasal continuous positive airway pressure therapy. Circulation 1999, 100(7):706-712.

5 Considine R,and Van Gaal L. Human leptin: from an adipocyte hormone to an endocrine mediator. EJE (2000), 143: 293311.

6 Cooper B, White J, Ashworth L, Alberti K, Gibson G. Hormonal and metabolic profiles in subjects with obstructive sleep apnoea syndrome and the acute effects of nasal continuous positive air way pressure (CPAP) treatment. Sleep 1995;18: 172-179.

7 de-Courtin M, Zimmet and A Hodge. Hyperleptinemia: The missing link in the metabolic syndrome? Diabetes Med.(1997), 14; 200-208.

8 EmilssonV, Liu $M$,Cawthorn et al. Expression of the functional leptin receptor mRNA in pancreatic islet and direct inhibitory action of leptin on insulin secretion .Diabetes (1997). 46: 313-336.

9 Fit zpatrick M,.Leptin and the obesity hypoventilation syndrome: a leap to faith?

10 Grunstein K, Wilcox I, Yang T. Snoring and sleep apnoea in men: association with central obesity and hypertension. Int $\mathrm{J}$ Obes 1993; 17:533- 540.

11 Grustein R, Stenlof K, Hedner J, Sjostrom L. Impact of obstructive sleep apnoea and sleepiness on metabolic and cardiovascular risk factors in the Swedish obese subjects(SOS) study. Int $\mathrm{J}$ Obes Related Metab Disord 1995;19: 410-4

12 Holley H, Milic-Emili J,Becklake M,et al. Regional distribution of pulmonary ventilation and perfusion in obesity. J Clin Invest 1967;46:475-481

13 Maccario M ,Ramunni J, Oleandri S, Procopio M, et al. Relationship between IGF-1 and age, gender, body mass, fat distribution, metabolic and hormonal variables in obese patients. Int $\mathrm{J}$ Obes Relat Metab Disord 1999 ; 23: 612-618

14 Meigs J. Invited commentary: insulin resistance syndrome? Syndrome $\mathrm{X}$ ? Multiple metabolic syndrome ? A syndrome at all ? Factor analysis reveals patterns in the fabric of correlated metabolic risk factors. Am. J Epidemiology 2000; 152(!0): 908-11.

15 Meslier N ,Gagnadoux F, Giraud $\mathbf{P}$, Person C, et al. Impaired glucose-insulin metabolism in males with obstructive sleep apnoea syndrome. Eur Respir J 2003; 22:156-160.

16 Phipps P, Starritt E, Caterson I, Gruuuunstein R. Association of serum 
leptin with hypoventilation in human obesity. Thorax 2002; 57(1) 75-76.

17 Schafer H, Pauleit D, Sudhop T, GouniBerthold I, et al .Body fat distribution, serum leptin, and cardiovascular risk factors in men with obstructive sleep apnoea. Chest 2002; 122(3): 829-839.

18 Spiegelman B, Flier J. Adipogenesis and obesity: rounding out the big picture. Cell 1996; 87: 377- 389.

19 Steven RC, Lynn M Julie AM, Peter MA, John PH .Obstructive sleep apnoea is independently associated with an increased prevalence of metabolic syndrome.

20 Stoohs R, Facchini F, Guilleminault C. Insulin resistance and sleep disordered breathing in healthy humans. Am J Respir Crit Care Med 1996; 154: 170- 174.
21 Strohl K, Novak R, Singer W, et al. Insulin levels, blood pressure, and sleep apnoea. Sleep( 1994) 17:614-618.

22 Spiegelman B, Flier J. Adipogenesis and obesity: rounding out the big picture. Cell 1996; 87: 377- 389.

23 Vgontzas A, Bixter E, Chrouses G. Metabolic disturbance in obesity versus sleep apnoea: the importance of visceral obesityand insulin resistance. J Int Med (2003); 254(1): 32-44.

24 Walder K, Pilippis S, Clark et al. Leptin inhibits insulin binding in isolated rat adipocytes. J Endocrinol. (1997); 155: R5-R7.

25 Young T, Palta M, Dempsey J, et al .The occurrence of sleep-disordered breathing among middle-aged adults. N Engl J Med 1993; 328:1230-1235 


\section{توزيع دهون الجسم، مستوى هرمون الليبتين بالام ومقاومة الجسم التوم}

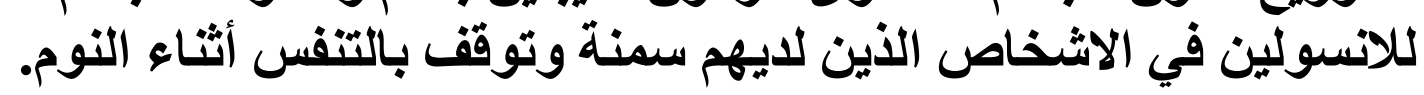

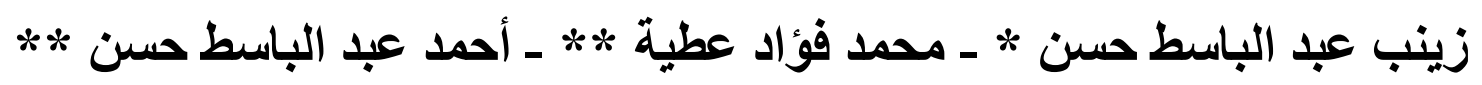

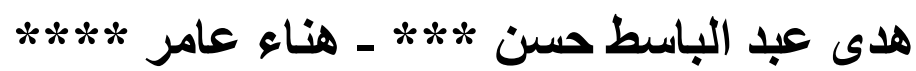

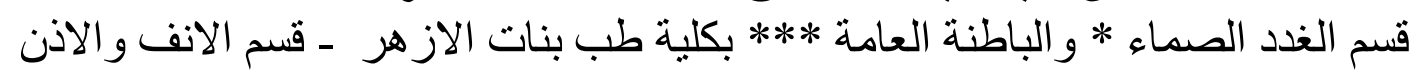

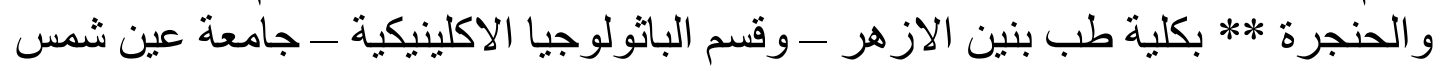

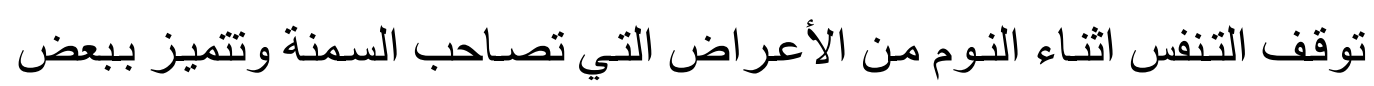
التغير ات في الهرمونات و التمثيل الغذائي بالجسم.

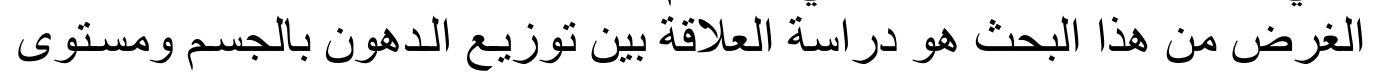
هرمون اللييتين و التنثيل الغذائي للجلوكوز و الانسولين لئلين في الاشخخاص اللذانين يعانون من توقف التنفس الثناء النوم. اجرى هذا البحث على 23 شخصاه يعانون من السمنه وتمت مقارنتهم ب 10 اثخاص اصحاء منماتلين في السن و النوع كعينه ضابطة.

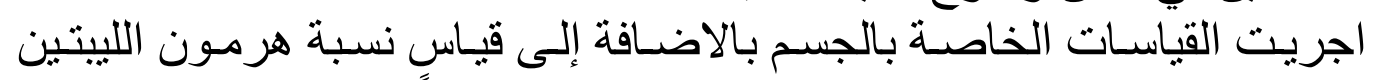

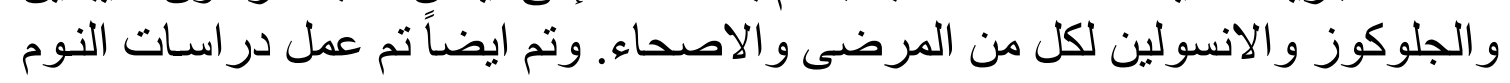

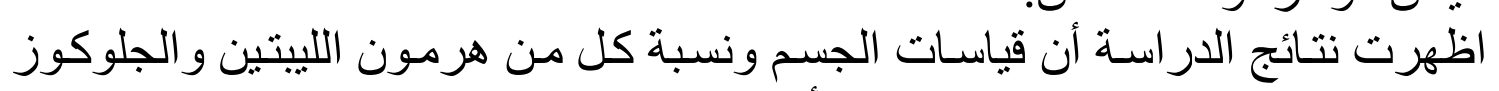

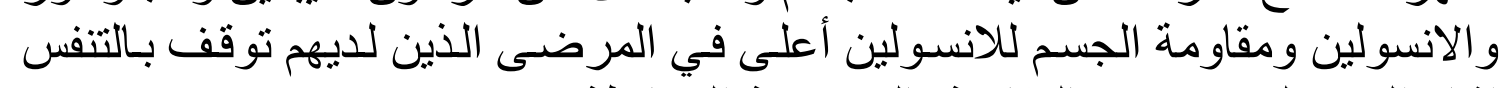

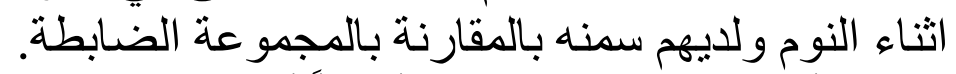

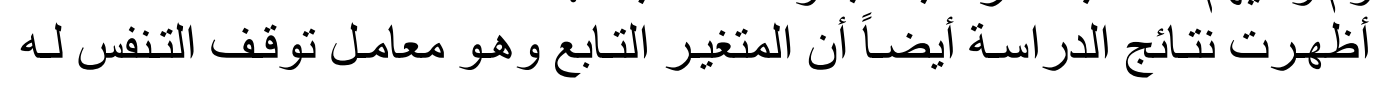

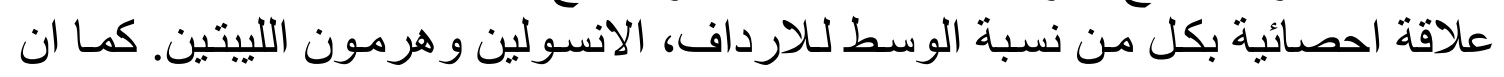

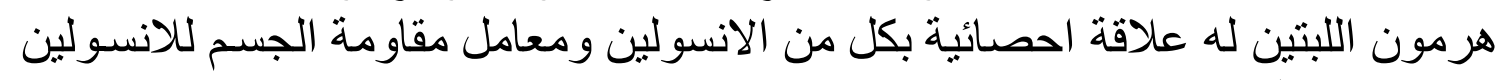

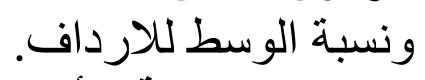
الخلاصة:- أن هناك علاقة طردية بين توقف التنفس اثثاء النوم من ناحية وكل

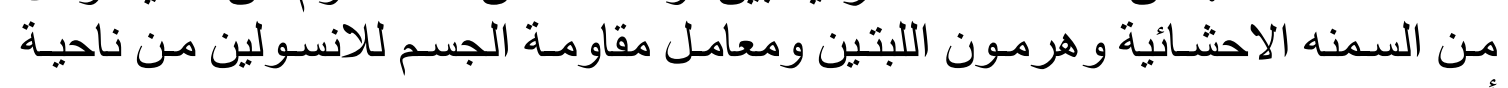

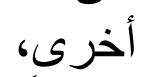
وأيضاً بين كل من هرمون اللييتين و السمنه ومعدل مقاومة الجسم للانسولين. 